\title{
A INVISIBILIDADE DA PESSOA TRANSGÊNERA NA PREVIDÊNCIA SOCIAL
}

\author{
Fernando Nunes Pestana* \\ Litiane Motta Marins Araujo*
}

\section{RESUMO}

A evolução e os reclamos da sociedade tendem a levar o Legislador a inserir no ordenamento jurídico previdenciário o instituto do amparo e conversão mitigada do tempo de contribuição da pessoa transgênera para que ela se aposente, que em outros casos já é possível e vem sendo aplicado pelo Judicário antes mesmo da sua normatização. A sociedade, ainda com viés preconceituoso, não se diz pronta a debater o tema. $\mathrm{O}$ que faz surgir dúvidas quanto a sua aplicação, quais são os critérios para a sua fixação.

Palavras-Chave: Transgêneros. Aposentadoria. Previdência Social. Dignidade da Pessoa Humana.

\section{THE INVISIBILITY OF THE TRANSGENIC PERSON IN SOCIAL SECURITY}

\begin{abstract}
The evolution and demands of society tend to lead the Legislator to insert in the social security legal system the protection institute and mitigated conversion of contribution time of transgender person to retire, which in other cases is already possible and has been applied by the Judiciary even before its normalization. The society, still biased bias, does not say ready to debate the issue. Which raises doubts as to its application, what are the criteria for its fixation.
\end{abstract}

Keywords: Transgender. Retirement. Social Security. Dignity of human person.

\section{INTRODUÇÃO}

O Artigo busca problematizar a pertinência do tema universalidade da cobertura e do atendimento na política de previdência social, (art. 194, I da CR/88), em relação às minorias, em especial, o grupo transgênero da população LGBTTT $^{1}$.

Como é cediço, toda essa população sofre discriminação e hodiernamente assiste-se a violação de seus direitos humanos.

Debruçar o olhar à complexidade do tema, coaduna-se com as demais políticas públicas, como a do Brasil sem homofobia ${ }^{2}$ a qual infere uma proposta intersetorial onde

\footnotetext{
* Fernado Nunes Pestana. Mestre em Administração UNIGRANRIO, orientado pelo Prof. Dr João Felipe H. Sauerbronn. Bacharel em Direito UNIGRANRIO, orientado pela Profa. MSC. Litiane Motta. E-mail: litiane.motta@unigranrio.edu.br

* Littiane Motta Marins Araujo. Mestre em Direito Publico e Novos Direitos pela UNESA RJ. Coordenadora Adjunta do Curso de Direito da UNIGRANRIO/RJ. E-mail: fnpestana@gmail.com

${ }^{1}$ Lésbicas, Gays, Bisexuais, Travestis, Transexuais e Transgêneros.
} 
abrange ações nos setores da Cultura, Educação, Saúde, Segurança Pública e Trabalho. Não vislumbrou, a época, a Previdência Social, ora provocada pelo presente estudo.

A Constituição Cidadã e demais legislações infra tratam dos mais variados temas: racismo, idoso, deficiente, criança, índio, tortura, mas esquecem-se de tratar e enxergar essa parcela da sociedade que sofre todos os dias as mais diversas formas de discriminação, agressões, torturas, assassinatos, impede-se o acesso aos estudos, trabalho, construção de família.

Não há vasta literatura sobre o tema específico. E por ser tão importante e atual, o Direito como ciência social, não poderia deixar de abordá-lo e oferecer debates, discussões, propostas de incluir na Constituição a equiparação a crime hediondo qualquer atentado contra os direitos a essa comunidade.

Ações afirmativas também chamadas de discriminações positivas, não visam diferenciar para excluir, pelo contrário, diferenciam para incluir. Consistem em políticas públicas ou programas privados que buscam a redução das desigualdades sejam elas, de caráter étnico, racial, social, física, etc. Assim, são concedidas "vantagens compensatórias" para a busca do equilíbrio. Grande parte da doutrina afirma que essas ações devem ter caráter temporário, até que seja sanado o desequilíbrio.

Enxergar o outro como irmão, trazê-lo para o seio social totalmente integrado, contribuindo para uma sociedade mais justa e igualitária, diminuindo as diferenças, congregando a diversidade cultural, fazê-lo crer na sua produtividade intelectual e econômica contribuindo para o progresso da nação.

“A "subclasse" é um grupo heterogêneo de pessoas que tiveram seu "bios" (vida social reconhecida) reduzido a "zoë" (vida animal com todas as ramificações reconhecidamente humanas anuladas)". (BAUMAN, 2005, p. 46)

Bauman (2005) se referia aos refugiados, sem Estado/sem Identidade, negado o direito à presença física dentro de um território sob lei soberana, exceto em "não lugares" especialmente planejados. Aqui, a comparação se encaixa.

Marcelo Novelino (2014) nos faz pensar se as ações afirmativas seriam ou não constitucionais.

\footnotetext{
${ }^{2}$ Programa de Combate à Violência e à Discriminação contra GLBT e de Promoção da Cidadania Homossexual, 2004.
} 
Pelo viés contrário: As ações afirmativas seriam políticas imediatistas e inapropriadas para solucionar o problema de forma definitiva; afronta os princípios constitucionais da igualdade, da não discriminação.

Pelo anverso: cumprem os valores estruturantes do Estado, construção de uma sociedade justa e solidária (princípio da solidariedade) e busca a redução das desigualdades sociais (princípio da igualdade). Visa contribuir para o "surgimento de uma sociedade mais diversificada, aberta, tolerante, miscigenada e multicultural”. (NOVELINO, 2014, p. 466)

De sorte que o STF - Supremo Tribunal Federal já se pronunciou várias vezes adminitindo a constitucionalidade das políticas de ações afirmativas.

A abordagem etnográfica do presente Artigo tem carater de investigação científica. Serve para demonstrar no campo das pesquisas qualitativas, especificamente as de interesse pelos estudos das desigualdades sociais e dos processos de exclusão. Introduz os atores sociais com uma participação ativa e dinâmica e modificadora das estruturas sociais.

A etnografia é um processo conduzido pelo olhar questionador do etnógrafo. A utilização de técnicas e procedimentos etnográficos, não seguem padrões rígidos ou prédeterminados. (MATTOS, 2011)

Tangenciando o campo da etnografia, o presente Artigo procura esclarecer que praticamente não existe uma política de atenção integral e inclusão do Transgênero e dizer a ele que é possível sim ter seu direito reconhecido na previdência social.

Dizer não à essa parcela da sociedade é abrir caminho para que outros direitos e garantias possam ser suprimidos de toda a sociedade.

\section{O ESTADO DEMOCRÁTICO DE DIREITO. UNIVERSALIDADE DA COBERTURA E ATENDIMENTO NA PREVIDÊNCIA SOCIAL}

O Brasil inaugura sua previdência social nos anos 20 do século passado com a criação das CAPs - Caixa de Aposentadorias e Pensões sob a modalidade de gestão privada, para atender um tipo específico de trabalhador, o ferroviário. Ao qual irá se estender à várias empresas ao longo da década. Ampliada, nos anos 30, a cobertura para atender por categoria profissional e gestão pública transformando as CAPs em IAPs - Institutos de Aposentadoiras e Pensões. Note-se que o trabalhador rural, antes de 1988, somente tinha direito a aposentadoria por idade com $50 \%$ do salário mínimo e $30 \%$ do referido para pensão por morte, hoje esses direitos estão equiparados. 
Um parêntese, o Estado de Bem-Estar social surgiu como contraponto necessário ao crescimento do comunismo. (IBRAHIM, 2011)

O Governo Central, em 1966/7, unifica todos os IAPs em um único Instituto, o INPS - Instituto Nacional de Previdência Social, que de forma acertada corrige as distorções que havia entre os antigos Institutos, haja vista, determinada categoria profissional obtinha mais vantagens do que outras, face sua organização e luta ao enfrentamento com o Estado $^{3}$ e o Capital.

Em 1990, o governo Collor extingue o INPS e cria o INSS - Insituto Nacional do Seguro Social, abrindo um viés de seguradora social, portanto com caráter obrigatório e contribuitvo, se distanciando da tutela única estatal.

Alerta-se que os empregados domésticos somente adquirem o status de trabalhador em junho de 2015 com a Lei Complentar 150, acabando com um dos últimos resquícios da escravidão.

A previdência social, hoje, atende a $100 \%$ da população, i) empregado, ii) empregado doméstico, iii) contribuinte individual (autônomo), iv) avulso (estivador), v) segurado especial (rural, pescador, índio) e o facultativo (estudante, dona de casa).

Dessa forma, pode-se inferir que todos os trabalhadores estão agasalhados pela previdência social. Porém, a realidade nos mostra que nem todas as pessoas contribuintes da previdência social possuem os mesmos direitos e são equiparados entre si. O transgênero é uma delas.

Esse breve histórico aduz que a luta por conquistas sociais é árdua e hercúlea. As elites dirigentes, desde a formação politica do Estado Nacional, não debruçam o olhar e somam esforços com intuito de resolver o problema social do povo brasileiro.

Somente a sociedade civil organizada, formulando políticas públicas de integração e cobertura social, exigindo o cumprimento da Constituição poderá obter seu reconhecimento.

Agora, põe-se diante de mais uma discussão: por que não atender ao transgênero na previdência social?

A legislação sobre o tema ainda mantém a separação de tempo de contribuição entre os sexos. Atualmente, para se aposentar por idade, o homem necessita de 65 anos e a mulher 60 anos.

\footnotetext{
3 "Este Estado é um conjunto de situações de fato, juridicamente qualificadas de determinada maneira e assim, finalmente, o sistema dessas normas jurídicas qualificadas nessa situação de fato, isto é, um ordenamento jurídico parcial, mais ou menos arbitrariamente destacado da totalidade do ordenamento Jurídico estatal" (KELSEN, 2012, p. 177).
} 
Nesse quesito que o presente trabalho demonstra que se uma pessoa transgênera resolva alterar sua condição do binômio masculino para feminino poderia, em tese, se aposentar mais cedo e o inverso se aposentaria mais tarde. Sem que isso altere o equilíbrio financeiro e atuarial ou que venha gerar déficits. (ASSOCIAÇÃO..., [20-])

\subsection{A dinâmica sociedade contemporânea mundial, mudanças de valores e condutas}

A sociedade, ainda hoje, discrimina diversos segmentos sociais, seja pela cor da pele, classe social, vestimenta, linguagem, comportamento, ideologia, enfim.

O cerne da questão foi abordar o contexto social em que vivem as pessoas "trans".

$\mathrm{Na}$ pesquisa etnográfica que o tema em si sugere, tangenciou outras classes sociais para mostrar que o quadro ainda é caótico.

$\mathrm{Na}$ Argentina, a atleta transexual Jessica Millamán ganhou o direito de disputar partidas profissionais de hóquei sobre a grama na categoria feminina, após ter sido impedida pela federação. (O DIA, 2017)

Na Chechênia, a ONU denuncia sequestros, tortura e assassinatos de LGBTs: "É crucial que os relatos de sequestros, tortura, espancamentos e homicídios de homossexuais sejam investigados". Alguns deles teriam sido praticados pelos próprios membros da família nos chamados "homicídios de honra" (NAÇÕES UNIDAS, 2017). O presidente da Chechênia prometeu "eliminar" todos os homens gays (...). (PRESIDENTE..., 2017)

Nos Estados Unidos, Trystan Reese parou de tomar testosterona para conseguir engravidar. O Bebê nasceu saudável e alegre. Ele e o companheiro, Biff Chaplow, possuem dois filhos adotados em 2011, decidiram ter um filho biológico e chamaram a atenção da imprensa internacional. (MACEDO, 2017)

Contudo, o Brasil tem avançado, a passos lento, na legislação infraconstitucional: a alteração do nome social no registro de identidade, a união homoafetiva, o casamento entre pessoas do mesmo sexo, o registro na certidão de nascimento de dois pais ou duas mães, dentre outros.

Em 2015, uma resolução da Secretaria de Direitos Humanos recomendou que estudantes transgêneros escolham qual uniforme e qual banheiro usar e que devem ser chamados por seus nomes sociais. A medida tem um peso brutal para o (a)s trans: "Hoje, 90\% da população trans trabalha na prostituição porque não teve uma educação formal". "Se não houver essa facilidade eles irão abandonar os estudos". (ROSSI; NOVAES, 2015)

Porém, ainda vigora um preconceito e discriminação sem precedentes em qualquer outro lugar no mundo. O Brasil é o país que detém o maior índice de assassinatos de pessoas LGBT. Gera impacto nas contas públicas, diretamente na previdência social (pensão por 
morte). Raramente a Autarquia previdenciária consegue entrar com ação de regresso contra o autor do dano. Não há uma política de enfrentamento por parte da Administração Pública em reaver seus prejuízos com os mais variados tipos de mortes (por acidente de trabalho, no trânsito, nos hospitais, etc.).

Há uma escalada da violência no Brasil de uma maneira geral. A Pesquisa Datafolha/Fórum Brasileiro de Segurança Pública diz que: 50 milhões de brasileiros têm parente ou amigo assassinado. Mostra ainda que 16 milhões de pessoas perderam um parente ou amigo morto pela polícia. O debate sobre as vítimas dos homicídios acontece, porém pouco se fala sobre "as pessoas que ficam". "Estamos falando de 60 mil vítimas de homicído/ano". As mortes prematuras são pessoas que deixam de produzir. (CAESAR; REIS, 2018)

O Brasil é um dos países recordista em violência de gênero. Diz o Relatório da Associação Internacional de Lésbicas, Gays, Bissexuais, Transgêneros e Interssexuais (ILGA), em 2016 foram 343 homicídios de LGBTs, quase um morto por dia. É preciso mudar a cultura da intolerância/violência contra os LGBTs. E isso se faz na escola.

Os avanços eram lentos nos governos passados, porém, no governo em exercício, respaldado pelos setores mais retrógrados do País, a agenda é só retrocessos: um dos candidatos para a Presidência, Jair Bolsonaro, disse: "gay é falta de porrada". Outro presidenciável, o tucano João Doria, é entusiasta do projeto Escola Sem Partido. (SUSTENTAÇÃO..., 2017)

O potencial de compras LGBT é estimado em $\mathrm{R} \$ 419$ bilhões no Brasil. O que equivale a $10 \%$ do PIB. Essas estatísticas são subavaliadas. Segundo a Out Leadership, associação internacional de empresas que desenvolve iniciativas para o público gay, informa que nenhum país inclui em seu censo estatísticas sobre a população homossexual. Na Europa, o potencial de consumo é estimado em US\$ 873 bilhões e nos EUA, chega a US\$ 760 bilhões. As empresas estão de olho num público mundial que tem nada menos do que US\$ 3 trilhões para gastar ao ano. O que equivale ao PIB da França.

O IBGE, em 2010, informa que há 67 mil casais formados por pessoas do mesmo sexo, $(0,18 \%)$. A população homossexual no Brasil é estimada em 20 milhões (10\%).

No Brasil, os Bancos, interpretaram e formularam propostas para esse público. Desde os anos 2000, o Banco Real/Santander oferece a possibilidade de que duas pessoas do mesmo sexo possam compor renda para acesso ao crédito imobiliário. A Caixa Econômica Federal seguiu a mesma linha e não impõe restrições para a aquisição da casa própria. 
O setor de turismo, mais sensível e dinâmico, sempre esteve atento ao potencial de consumo dos gays. Associação Brasileira de Turismo LGBTS informa que o movimento é de R\$ 150 bilhões/ano. (SCRIVANO; SORIMA NETO, 2015)

A relevância e justificativa do tema é mais do que urgente. Combater a cultura do ódio e estigmatização de camadas sociais. Seja por opção sexual, religiosa, de cor da pele, de ideologia política, etc. $\mathrm{O}$ avanço social passa pelo aceitar as diferenças e respeitá-las. Tratar os iguais de forma igual e os desiguais de forma desigual na medida de suas desigualdades.

O Estado brasileiro ainda não incorporou e enxergou que essa parcela da sociedade consome, produz, trabalha, aufere renda, gerando riquezas e, portanto, necessitam do olhar das políticas públicas, especificamente, da previdência social.

Recentemente, uma pesquisa encomendada pala AMBEV junto ao IBOPE, identificou que o preconceito está presente no dia a dia dos brasileiros. Os dados revelam que $83 \%$ dos brasileiros não se consideram preconceituosos, porém $70 \%$ já fizeram algum comentário quadrado. Frases do tipo: "pode ser gay, mas não precisa beijar em público" (25\%) e "isso é coisa de viado" (23\%) disseram.

Não por acaso, o Brasil é o país onde um jovem negro é assassinado a cada 23 minutos, seis mulheres são estupradas a cada hora e 340 pessoas LGBTs, em 2016, foram assassinadas em crimes de ódio. (SALES, [2017])

O Censo Demográfico de 2010, do IBGE, pela primeira vez, registrou as relações homoafetivas $(0,1 \%)$ ou 60000 unidades domésticas das cerca de 57 milhões no País (PLANO..., 2014). Fica evidente que esse número não representa a realidade, talvez por medo de se declararem.

O Relatório sobre violência homofóbica no Brasil, 2012, produzido pela Secretaria de Direitos Humanos da Presidência da República (SDH/PR), traz a preocupação para o seio do Governo pela primeira vez. É o primeiro Relatório com dados oficiais sobre violações homofóbicas, lésbofóbicas e transfóbicas produzido na América Latina. Mas, ainda carece de informaçãoes referentes à segurança pública para a União. Os boletins de ocorrências policias não contém o campo relativo a orientação sexual, identidade de gênero ou possível motivação homofóbica.

O Brasil vive atualmente um movimento paradigmático em relação aos direitos humanos da população LGBT. Se por um lado houve conquistas de direitos historicamente resguardados por uma elite heteronormativa, por outro assiste-se a aterradora reação dessa 
mesma elite em sua pretensão de perpetuar o alijamento desses sujeitos e seus afetos. (BRASIL, 2013)

O Informe de Previdência Social, 2015, diz que não há nenhum dado sobre a quantidade de pessoas trans que acessam os benefícios da previdência. Faz-se mister que haja um reordenamento nas políticas de educação e trabalho, face aos elevados níveis de discriminação, muitas mulheres transexuais são analfabetas funcionais devido à exclusão sofrida no sistema educacional (44\%) e vivem como profissional do sexo.

No campo da Saúde existe diretriz para inclusão das pessoas trans. Em 2011, foi instituída a Política Nacional de Saúde Integral de LGBTT, com a garantia e acompanhamento de cirurgia de redesignação sexual. (SOUZA, 2015)

Já dentro das políticas de Assistência Social, têm-se dificuldades em reconhecer as demandas específicas da população transgênera, por seu caráter universalista das ações e programas por meio do SUAS - Sistema Único da Assistência Social. (SOUZA, 2015)

Toda essa abordagem (re) afirma que as instituições de proteção social precisam olhar para as parcelas da população que são marginalizadas, criando ações, programas e planos que garantam às pessoas a possibilidade de se sentirem livres, seguras e conscientes no exercício de seus direitos e deveres enquanto cidadãos usando a força viva do Direito para ensejar as mudanças necessárias ${ }^{4}$.

\subsection{Ações afirmativas, direitos humanos, dignificação da pessoa transgênera, inclusão social, respeito ao próximo}

O Direito, em forma de legislação, normalmente, divide seus argumentos em fundamentação filosófica e jurídica, para dar sentido ao texto positivado. A fundamentação filosófica das ações afirmativas no magistério de Ronald Dworkin (apud Moraes, 2003) ensina que a doutrina estadunidense prestigia a teoria da justiça distributiva como necessária não como compensação de minorias ou grupo sociais por discriminações passadas contra eles, mas como contribuição para que a distribuição das posições de prestígio e influência benficie a sociedade com um todo.

\footnotetext{
4 “Segundo IHERING, 2004 “o direito não é mero pensamento, mas sim força viva. Por isso, a Justiça segura, numa das mãos, a balança, com a qual pesa o direito, e na outra a espada, com a qual o defende. A espada sem a balança é a força bruta, a balança sem a espada é a fraqueza do direito. Ambas se completam e o verdadeiro estado de direito só existe onde a força, com a qual a Justiça empunha a espada, usa a mesma destreza com que maneja a balança".
} 
Já a fundamentação jurídica, encontra-se em mandamentos constitucionais, a exemplo:

Constituição da Namíbia, art $23 \S 2^{\circ}$ : impedirá o Parlamento de aprovar legislação que possibilite, direta ou indiretamente, o desenvolvimento de pessoas dentro da Namíbia que tenham estado socialmente, economicamente ou educacionalmente, em desvantagem devido a leis ou práticas discriminatórias passadas, ou à implantação de políticas ou programas voltados para a correção de desequilíbrios sociais.

Constituição da Índia, art $15 \S 4^{\text {o: }}$ impedirá o Estado de elaborar qualquer disposição especial para o progresso de qualquer classe social e educacionalmente atrasada de cidadãos ou das Castas Programadas e Tribos Programadas.

Tratados Internacionais, Convenção sobre a Eliminação de todas as Formas de Discriminação contra a Mulher, art. 4o, inc. I: A adoção pelos Estados-Partes de medidas especiais de caráter temporário destinadas a acelerar a igualdade de fato entre o homem e a mulher (...). (MORAES, 2003)

Como demonstrado, ainda há Estados Nacionais com normas rígidas contra direitos e a dignificação da pessoa humana, principalmente se esta se declarar transgênera.

Em questão, o transgênero não é uma criação abastrata. O que é ser transgênero?

A psicóloga Camila Hoffmann (2016): a maioria das pessoas diz só haver dois papéis: o homem e a mulher. $O$ transgênero é aquele que não se identifica, nem se expressa, segundo o "esperado" para o seu gênero sexual, normalmente tem a sensação de estar no corpo errado, sofrendo um desconforto constante em relação ao próprio sexo.

O psicólogo e psicanalista Rafael Cossi (apud D’ALAMA, 2013) diz que transexual é a pessoa que tem um transtorno mental e de comportamento sobre sua identidade de gênero, ou seja, nasce biologicamente com determinado sexo, mas se vê pertencente a outro e cogita fazer tratamentos hormonais e cirurgia para mudar o corpo físico.

Qual a diferença entre transgênero e transexual?

- transgênero - quer poder se expressar como o sexo oposto (usando roupas, por exemplo), mas não tem necessidade de modificar sua anatomia corporal.

- transexual - sente que sua anatomia não corresponde à sua identidade e tem um forte desejo de modificar o corpo, através da terapia hormonal e da cirurgia de redesignação sexual. 
Transexuais são transgêneros que fazem a transição de gênero, com ou sem a cirurgia de readequação genital. Travestis são transgêneros que, tradicionalmente, no Brasil, modificam seu corpo com o objetivo de atuar na indústria do sexo, mas em geral não fazem a cirurgia de readequação genital: o silicone dos seios convive com o órgão sexual masculino e elas estão felizes assim. Drag queens são homens que gostam de se "montar" como mulher em algumas ocasiões. Elas quase sempre são gays, e quase nunca querem ser mulheres em tempo integral.

O Transgênero é confundido com homosexual, travesti, etc. Como dar sentido a esse corpo se ele não está enquadrado no rol das significações vigentes, essa linha que associa o trinômio sexo (homem ou mulher), gênero (masculino ou feminina) e desejo (a orientação sexual) pela heteronormatividade? Esses corpos adquirem a denominação do "trans": aqueles que residem no entre-lugar das definições binárias. As sociedades parecem não querer falar sobre, mesmo reconhecendo a sua existência. (LEITE, 2014)

O Movimento Transgênero se distingue do Movimento LGBTTT por ter reivindicações específicas, como a luta contra a medicalização e patologização da transexualidade. Aqui, o Movimento parece demonstrar ou não perceber que deveriam se auto incluir para serem vistos pela previdência social. (ÁVILA; GROSSI, 2010)

O exemplo do filme: “A Garota Dinamarquesa” (The Danish Girl, 2015). Ilustra a questão. Traz a conturbante história da dinamarquesa Lili Elbe (1882-1931) é conhecida por ser uma das primeiras pessoas transgêneras a fazer a cirurgia de mudança de sexo (em 1930). O filme acerta ao explicar o que é a transgeneridade e seu potencial de fazer a sociedade progredir em um sentido de igualdade quando essas pessoas têm seus direitos assegurados.

Dos idos pretéritos para os dias atuais. Transgêneros famosos que se assumiram e tornaram-se ícones:

A transexual Lea T, modelo famosa, filha do ex-jogador Toninho Cerezo, foi alvo de muito preconceito durante sua infância. Ela não se aceitava no gênero masculino, disse que se arrepende de ter feito a troca de sexo e que não aconselha o procedimento para ninguém. "Eu achava que a minha felicidade era embasada na cirurgia. Fiquei mais à vontade, mas um pênis e uma vagina não trazem felicidade para ninguém. Nunca vou ser $100 \%$ mulher (...)".

Segundo o psicólogo Rafael Cossi, ver a cirurgia como forma de "normalização" social, para se adequar ao pensamento heterossexual, é uma das maiores críticas à mudança de sexo. 
O Ex-transexual, de 76 anos, Walt Heyer foi contundente contra a mudança de sexo: “A cirurgia não corrige nada, apenas mascara problemas psicológicos”. Ele já passou por dois procedimentos de mudança de sexo. Nascido homem, foi induzido a pensar que era uma mulher no corpo errado, aos 50 anos decidiu fazer uma nova cirurgia para desfazer a primeira. Mesmo com o corpo "maculado", ele conseguiu se casar novamente "se mais pessoas estivessem cientes da história escura e conturbada da cirurgia de mudança de sexo, talvez não seríamos tão apressados em empurrar as pessoas para isso". (CHAGAS, 2007)

Laerte Coutinho. Cartunista e chargista mais famosa do Brasil. Assumiu sua transexualidade aos 57 anos e voltou a mídia para a questão da identidade de gênero no país. Em 2010, revelou publicamente ser uma mulher trans através do crossdressing, basicamente se "montando", usando roupas que as pessoas consideram se encaixar melhor no sexo oposto.

Roberta Close, só teve seu nome e gênero legal alterados em 2005. Sua cirurgia de redesignação sexual foi em 1989, na Inglaterra, buscou a legalidade em 1992, sendo negada em 1997. Tendo que passar por especialistas psicológicos e médicos para comprovar que ela possuía aspectos hormonais femininos. (DEZ..., [201-])

$\mathrm{Na}$ Inglaterra, encontra-se o estudo acadêmico sobre o tema extraído das tropas militares. O projeto "Dry Your Eyes Princess" (Seque seus olhos, princesa, em tradução literal) Os militares transgêneros que viram o Exército como 'forma de terapia'. (Emma Vickers, historiadora da Universidade John Moores, de Liverpool). 'Eu atuava num papel. Era a maior camuflagem que eu poderia ter na minha vida', diz participante. "Eu apanhei do meu pai após o médico dizer a ele que eu gostaria de ser uma menina". (BBC, 2016)

\section{O QUE DIZEM OS TRIBUNAIS PELO MUNDO: DIREITO À AUTODETERMINAÇÃO DO TRANSEXUAL}

A Europa, da luta de seus povos por diginidade e democracia, parece ter entrado em retrocesso. O Tribunal de Estrasburgo (França), o mais importante do mundo, dos Direitos Humanos, por unanimidade, os 47 juízes dos 47 países do Conselho da Europa sentenciou literalmente: "não existe casamento homossexual". O parecer foi baseado em uma série de recitais filosóficas e antropológicas baseadas na ordem natural, senso comum, relatórios científicos e, no direito positivo. Segundo o art 12 da Convenção Europeia dos Direitos Humanos (equivale ao art 17 do Pacto de San Jose e art. 23 do Pacto Internacional sobre os Direitos Civis e Políticos). Na resolução histórica, o Tribunal decidiu sobre o que realmente é a família. "O conceito tradicional de casamento, ou seja, a união de um homem e uma 
mulher", "os Estados são livres para reservar casamento com apenas casais heterossexuais." (TRIBUNAL..., 2014)

Ao passo que o Brasil avança nas suas propostas de mudanças para construção e fortalecimento do direito do transexual. Recentemente, encontra-se julgados dos Tribunais Superiores que assente, aquiesce e concorda com o posicionamento de operadores do Direito em defesa da causa. STJ: RE 0017952-08.2015.8.21.0001, Rel. Min Luis Felipe Salomão, 10.05.17: Transexual tem direito a alterar registro civil mesmo sem cirurgia:

\begin{abstract}
A superação de preconceitos e estereótipos, bem como o exercício da alteridade, isto é, a capacidade de se colocar no lugar do outro, notadamente em razão do contexto social atual: uma sociedade que adota um sistema binário de gênero, dividindo as pessoas entre mulheres (feminino) e homens (masculino), e que marginaliza e/ou estigmatiza os indivíduos fora do padrão heteronormativo.” (...) A exigência de cirurgia para viabilizar a mudança do sexo registral "vai de encontro à defesa dos direitos humanos internacionalmente reconhecidos (...), por condicionar o exercício do direito à personalidade à realização de mutilação física, extremamente traumática, sujeita a potenciais sequelas (como necrose e incontinência urinária, entre outras) e riscos (inclusive de perda completa da estrutura genital).
\end{abstract}

Gilmar Mendes ([2010], p. 5) leciona que "pensar a igualdade segundo o valor da fraternidade significa ter em mente as diferenças e as particularidades humanas em todos os aspectos”. A tolerância, segundo o princípio da igualdade, exige a consideração do outro respeitando as suas peculiaridade e idiossincrasias. A igualdade só pode ser igualdade numa sociedade pluralista quando há reconhecimento do direito à diferença e, em consequência, aceitação das minorias.

Advogada Robeyoncé de Lima, 28 anos, foi a primeira advogada trans do Norte e Nordeste a conseguir nome social na carteira da OAB, ela deu o nome à turma, 2015, UFPE: "Quero (...) lecionar na própria universidade onde me formei. Quero exercer a advocacia, ajudar pessoas e ver seus sorrisos, o seu direito assegurado. Isso, nenhum honorário paga”. (ALVES, 2017)

Primeira advogada transexual a atuar no STF: Gisele Alessandra Schmidt, em 07.06.17, defendeu que os transexuais tenham o direito de trocar de nome e sexo no registro civil mesmo sem fazer cirurgia. "Sinto que estou fazendo história. Mas se estou aqui perante vossas excelências é porque sou uma sobrevivente". "Sobrevivi ao apedrejamento moral e físico, à proibição de estar na rua e nos espaços públicos, mesmo que à luz do dia". "Estou aqui perante Vossas Excelências hoje não apenas por mim, mas sim por toda uma população de pessoas que ainda sofre imenso constrangimento e têm sua dignidade violada diariamente. Negar a uma pessoa o direito ao nome, à expressão de sua identidade, é negar o direito de existir. Requer-se a vossas excelências que não nos neguem esse direito”. Para a PGR (...) 
"impor a uma pessoa a manutenção de um nome em descompasso com a sua identidade é a um só tempo, atentatório à sua dignidade e comprometedor de sua interlocução com terceiros, nos espaços públicos e privados". (CASADO, 2017)

Segundo o cientista político Frederico de Almeida o argumento central levado por Gisele, (...) foi muito repetido pelos militantes do movimento negro (...). No fundo é isso: não somos apenas injustos porque distribuímos desigualmente as oportunidades, os direitos e a riqueza; somos profundamente injustos, cruéis mesmo, porque exterminamos os diferentes, os desiguais, os subordinados, os vulneráveis. (SUSTENTAÇÃO, 2017)

A universalidade da cobertura e do atendimento (art.194, I da CR/88) não incorpora, ainda, o conceito de transgênero. Pois, sabendo que uma pessoa ao alterar seu sexo, em tese, estaria ao abrigo da legislação deste novo sexo (Homem se aposenta aos 35 anos de contribuição e mulher aos 30 anos). O caminho passa pelo princípio da mitigação do direito, ou seja, quanto tempo o trabalhador contribuiu num sexo e após a sua mudança no outro? Incorre-se em erro se a mudança de sexo for do feminino para o masculino, haja vista que haverá aumento de tempo de contribuição? A população transgenera é tão siginificativa que causará impacto nas contas públicas da seguridade social? Usando-se, por analogia, os cálculos da aposentadoria especial do art 57 da Lei 8.213/91, correlação com o art 64 e seguintes do Decreto 3.048/99, quando este trabalhador é submetido a condições de trabalho que prejudiquem a saúde ou integridade física? O estudo do direito contemporâneo deverá debruçar o olhar sobre essas incógnitas.

Por hipótese, o estudo toma como base a fórmula do fator previdenciário, (art. $32 \S$ 11 do Dec.3048/99); e como exemplo uma pessoa "trans" do masculino para o feminino, posto que, em tese, traria desvantagens à arrecadação.

Como Tc, tempo de contribuição, no ato da aposentadoria, teríamos 30 anos (M) e não $35 \operatorname{anos}(\mathrm{H})$, poder-se-ía achar que o homem trans levaria vantagem e o seu inverso desvantagem. Não há pensar tão simploriamente. Deve-se sopesar o direito com a matemática. A melhor razão de equilibrío seria a mitigação desse tempo contributivo entre os sexos.

Exemplo: homem com 25 anos de Tc, falta-lhe (10 a) para completar os (35 a). Ao tornar-se trans, feminino, precisaria somente mais 05 anos. O que não seria justo. Aplicandose a regra de três teremos: (10 a) faltantes divididos por (35 a); encontra-se a taxa de 28,57\%. Aplicando-se a mesma taxa para o sexo feminino, implica que o tempo devido passa a ser $28,57 \%$ vezes (30 a) igual a 8,5710 anos de contribuição, que somados aos 25 anos já vertidos, perfaz um total de 33,5710 anos, 33 anos e 06 meses. 
Dessa forma, mantem-se o equilíbrio financeiro e atuarial; não há dizer que houve vantagem em trocar de sexo para poder se aposentar mais cedo e o princípio da dignidade da pessoa humana foi respeitado e atendida a legislação previdenciária. A própria previdência já aplica regras especiais de tempo de contribuição em alguns casos (Decreto 3048/99). A exemplo: 1) Aposentadoria por idade rural (art.51 do Dec 3048/99); 2) Aposentadoria especial de professor (art $56 \S^{\circ}$ ); 3) Aposentadoria especial (art 64) para segurados que tenha trabalhado sujeito a condições especiais que prejudiquem a saúde ou a integridade física; 4) Aposentadoria por tempo de contribuição e por idade do segurado com deficiência (art 70-A e seguintes).

\subsection{A aplicação das novas ideias no ordenamento jurídico e o impacto no orçamento previdenciário}

O Juiz, ao decidir a questão concreta, usa os princípios do seu livre convencimento pela ausência de regramento legal para que o decisório tenha efeito satisfativo perante a sociedade. Um caso recente, que dominou os jornais, foi o de um Juiz que cassou uma pensão por morte face a pessoa trans feminina ter optado pelo sexo masculino. O estudo mais uma vez demonstra que enquanto a norma não é editada toda sorte de decisão judicial pode surgir: Filha transexual de militar perde pensão da Marinha após mudar de nome e de sexo. Com base na legislação que beneficia, com pensão, as filhas (e não os filhos) de militares, a Marinha cancelou o benefício à filha transexual de um militar após ela mudar de nome e de sexo (de feminino para masculino) oficialmente. A decisão foi levada à Justiça e o juiz manteve o cancelamento da pensão da filha do militar (GOIS, 2017). A sentença parece dizer que a hermeneutica do Magistrado foi literal ou histórica. Posto que o legislador da época quis beneficiar o sexo feminino. Para os que defendem interpretação sociológica da lei, focaria o presente, quem sabe a decisão fosse favorável ao Autor da ação que viu seu benefício cancelado.

Observa-se que o governo central aplica constantemente desonerações e isenções fiscais das contribuições das empresas quando deseja incrementar ciclo produtivo para geração de emprego e renda ou fomento na economia. O contingente populacional transgênero da ordem de 10\%, esse percentual é estimativo e carece de estudos mais profundos, não traz em si a informação de que ao trocar de sexo a pessoa gerará défict previdenciário. Pelas estatísticas, o percentual de homenes trans é maior que o de mulheres trans, que, em tese, deveríam contribuir mais. 
O professor Balera defende o princípio da boa-fé e não aplicação de regra de mitigação e sim a regra mais favorável. O benefício deve ser concedido conforme o gênero do solicitante no momento do pedido, porém, não existe precedente nem determinação na legislação previdenciária que garanta. Seria necessária ação judicial, mesmo assim, os transexuais não têm seu direito garantido, já que o caso será analisado sem uma base jurídica e precedente no Judiciário. Afirma por hipótese que uma transexual, nasceu do sexo masculino, contribuiu, mas decidiu mudar de sexo próximo à época de sua aposentadoria, deveria ter direito ao benefício com a contabilização usada para as mulheres. Ao analisar o inverso, diz que o contribuinte deveria receber seu benefício como mulher, e não homem. "Essa é a natureza do sistema previdenciário, que é um direito protetor. Há de se observar a norma mais favorável nos casos". Para o Professor, o pedido de um benefício previdenciário feito por um transexual deveria ser negado apenas se fosse constatada uma intenção de driblar a lei. "Se um homem troca de sexo apenas para ter acesso ao benefício em menos tempo, como mulher, há aí uma situação diferente". Para resolver essa situação há a necessidade de alterações na legislação previdenciária. (FERNANDES, 2015)

Argentino vira mulher para antecipar aposentadoria: segundo seus colegas, a decisão foi tomada apenas para que possa se aposentar aos 60 anos, e não aos 65. "Seu caso levou bastante tempo e gerou discussões, mas foi autorizado. Inicialmente teve o pedido negado, mas se amparou na Lei de Identidade de Gênero. (FUNCIONÁRIO..., 2018)

\section{CONCLUSÃO}

O presente trabalho procurou abordar a temática dentro do escopo da nossa legislação previdenciária, trouxe o ethos dos aspectos positivos e contrários a questão.

A evolução histórica da previdência social no Brasil mostrou o quão difícil foi para o trabalhador ter seus direitos minimamente respeitados. A sociedade parece ainda estar deitada eternamente em berço explêndido. Ser o último país do mundo a abolir a escravidão e esta ainda perdurar aos dias de hoje. O trabalhador doméstico só foi equiparado a categoria de trabalhador urbano em 2015. Os jornais teceram críticas severas nesse posicionamento do parlamento. Vários representantes da elite vieram a público reclamar e bater panelas contra a LC 150/2015, quando a história diz que bater panelas é da classe social menos abastada. Disseram que agora não poderão contratar empregados domésticos, ou seja, uma total dessintonia com a sociedade. 
De sorte, que esse comportamento desrespeitoso com o próximo não é só prerrogativa brasileira, o estudo etnográfico encontrou mostras do comportamento de certas elites ao redor do mundo que beira a barbárie como o caso da Chechênia em que seu Presidente incita a caça aos do seu próprio povo, obrigando o parente deste a matá-lo, somente por uma opção política de comportamento diverso do binômio homem e mulher, masculino e feminino.

Noutra esteira, também, encontrou ação afirmativa como o caso da atleta da Argentina transgênera permitida a jogar hóquei entre as mulheres.

O artigo mostrou o quão estamos longe de alcançar a tão sonhada sociedade livre, justa e solidária (art $3^{\circ}$, I CR/88). A pesquisa encontrada diz que 50 milhões brasileiros possuem um amigo ou parente assasinado. Isso é mais do que a população inteira de diversos países. Esse número é assustador, traz um impacto negativo para os cofres da previdência social por causa do pagamento pensões. Sem necessidade de cálculos, pode-se afirmar que é $250 \%$ maior que toda a população LGBTTT do Brasil.

Essa mesma parcela da sociedade que representa $10 \%$ do PIB nacional, fez com que os Bancos modificassem sua postura em relação a eles e passou a oferecer financiamento habitacional.

Nesse diapasão, o estudo de marketing da AMBEV/SKOL deixou claro que 70\% dos brasileiros são preconceituosos com os Trans.

O informe da previdência social de 2015 revela que não possui dados estatísticos nem estudos de como atender a essa população. E o prórpio relatório critica que não existe política pública e atenção voltada para o problema em tela.

Nos últimos tempos, a discriminação e discursos de ódio estão sendo a tônica não só no seio de nossa sociedade como em vários outros países. A liberdade de expressão, liberdade religiosa, cor da pele, modo de se vestir, pensar diferente, torna-se um risco.

A união e congraçamento de ideias, em torno do tema, para ganhar forças, precisa da compreensão e comprometimento de toda a sociedade.

O estudo conseguiu comprovar que a fórmula de mitigação do tempo de contribuição traz a melhor temática para que se una ou sirva de base para outros trabalhos com intuito de mostrar um norte à discussão a fim de garantir os direitos a toda e qualquer pessoa à universalidade da cobertura e do atendimento. Está faltando o transgênero nessa equação.

O consenso político em torno da ideia da fórmula, mitigação do tempo de contribuição para os transexuais, mostra-se segura em dizer que não trará déficit orçamentário 
e nem precisará buscar outras fontes de custeio para sustentar os novos "entrantes" no bolo previdenciário. Ao contrário, pela parcela não substancial da população o binômio custeio x arrecadação tende a ser nulo ou superavitário, haja vista o número de trans do sexo masculino para o feminino ser maior que o seu inverso, gerando um tempo de pedágio análogo aos já consagrados em outros benefícios descritos no presente trabalho.

Por sua vez, trará menos resistência no parlamento a discussão do que simplesmente tentar introduzir uma mudança de regra legal baseada na boa-fé ou na norma mais vantajosa. A natureza da seguridade social é protetiva mas pressupõe sopesar com equilíbrio financeiro e atuarial.

O censo demográfico 2010, diz que há 52\% de mulheres e 48\% de homens no Brasil, alterar um ou dois pontos percentuais para qualquer lado não interfere no comportamento da receita global, até por que todos necessitam contribuir para poder fazer jus ao benefício.

O sistema capitalista sente a pressão e as tendências sociais, procura enrijecer aos reclamos e quando percebe que o custo da perda é maior do que o ganho, se amolda e conduz o processo produtivo.

Que surjam novos trabalhos mais profundos buscando o melhor desenho para o axioma apresentado.

Toda pessoa tem o direito à felicidade e já deveria estar esculpido no art. $6^{\circ}$ da carta maior.

\section{REFERÊNCIAS}

ALVES, Pedro. Advogada trans recifense consegue direito de retificar nome e gênero em registro de nascimento. G1, São Paulo, 15 jun. 2017. Disponível em:

$<$ https://g1.globo.com/pernambuco/noticia/advogada-trans-recifense-consegue-direito-de-retificar-nome-egenero-em-registro-de-nascimento.ghtml>. Acesso em: 27 maio 2018.

ASSOCIAÇÃO Nacional dos Auditores Fiscais da Receita Federal do Brasil. Brasília, [201-]. Disponível em:

$<$ https://www.anfip.org.br/buscando.php?buscador=Nesse+quesito+que+o+presente+trabalho + demonstra+que+se+uma+pessoa+transg $\% \mathrm{C} 3 \%$ AAnera+resolva+alterar+sua+condi\% $\mathrm{C} 3 \% \mathrm{~A}$ $7 \% \mathrm{C} 3 \% \mathrm{~A} 3 \mathrm{o}+\mathrm{do}+\mathrm{bin} \% \mathrm{C} 3 \% \mathrm{~B} 4 \mathrm{mio}+$ masculino+para+feminino+poderia $\% 2 \mathrm{C}+\mathrm{em}+\mathrm{tese} \% 2 \mathrm{C}+\mathrm{s}$ e+aposentar+mais+cedo+e+o+inverso+se+aposentaria+mais+tarde. + Sem + que + isso + altere $+o$ + equil\% $3 \%$ ADbrio+financeiro+e+atuarial+ou+que+venha+gerar+d\%C3\%A9ficits $>$. Acesso em: 26 maio 2018. 
ÁVILA, Simone; GROSSI, Miriam Pillar. Transexualidade e movimento transgênero na perspectiva da diáspora QUEER. In: CONGRESSO DA ASSOCIAÇÃO BRASILEIRA DE E ESTUDOS DA HOMOCULTURA, 5, Natal, 2010. Anais... Natal, 2010. Disponível em: $<$ http://nigs.paginas.ufsc.br/files/2012/01/TRANSEXUALIDADE-E-MOVIMENTOTRANSG\%C3\%8ANERO-NA-PERSPECTIVA-DA-DI\%C3\%81SPORA-QUEER-Simone\%C3\%81 vila-e-Miriam-Pillar-Grossi.pdf>. Acesso em: 27 maio 2018.

BAUMAN, Zygmunt. Identidade. Rio de Janeiro: Zahar, 2005.

BBC. Os militares transgêneros que viram Exército como 'forma de terapia'. G1, São Paulo, 3 jan. 2016. Disponível em: <http:/g1.globo.com/mundo/noticia/2016/01/os-militares-transgeneros-que-viram-exercitocomo-forma-de-terapia.html>. Acesso em: 27 maio 2018.

\section{BRASIL. SECRETARIA DE DIREITOS HUMANOS. Relatório sobre violência}

homofóbica no Brasil: ano 2012. Brasília, 2013. Disponível em: $<$ http://www.rcdh.es.gov.br/sites/default/files/RELATORIO\%20VIOLENCIA\%20HOMOFO BICA\%20ANO\%202012.pdf>. Acesso em: 27 maio 2018.

CAESAR, Gabriela; REIS, Thiago. Brasil registra quase 60 mil pessoas assassinadas em 2017. G1, São Paulo, 22 mar. 2018. Disponível em: < https:/g1.globo.com/monitor-da-violencia/noticia/brasil-registraquase-60-mil-pessoas-assassinadas-em-2017.ghtml>. Acesso em: 26 maio 2018.

CASADO, Letícia. Primeira advogada transexual a atuar no STF diz que é 'uma sobrevivente'. Folha de S. Paulo, São Paulo, 7 jun. 2017. Disponível em:

$<$ https://www1.folha.uol.com.br/cotidiano/2017/06/1891215-primeira-advogada-transexual-aatuar-no-stf-diz-que-e-uma-sobrevivente.shtml >. Acesso em: 27 maio 2018.

CHAGAS, Thiago. Ex-transgênero convertido diz que mudança de sexo é um erro que mascara problemas psicológicos. Gospel Mais, [S.l], 3 maio 2007. Disponível em:

$<$ https://noticias.gospelmais.com.br/ex-transgenero-mudanca-de-sexo-mascara-problemas-psicologicos90214.htm>. Acesso em> 27 maio 2018.

D'ALAMA, Luana. Transexual pode se descobrir já na primeira infância, dizem especialistas. G1, São Paulo, 03 mar. 2013. Disponível: <http://g1.globo.com/ciencia-e-saude/noticia/2013/03/transexual-pode-sedescobrir-ja-na-primeira-infancia-dizem-especialistas.html>. Acesso em: 27 maio 2018.

DEZ transgêneros famosos. Mensagens com amor, [S.1., 201-]. Disponível em: $<$ https://www.mensagenscomamor.com/10-transgeneros-famosos>. Acesso em: 26 maio 2018.

FERNANDES, Daniel. Especialista: Previdência é omissa com transexuais. Band, São Paulo, 18 jun. 2015. Disponível em:

<http://noticias.band.uol.com.br/noticias/100000757140/especialista-previdencia-e-omissacom-transexuais.html>. Acesso em: 27 maio 2018.

FUNCIONÁRIO público argentino vira mulher para antecipar aposentadoria. UOL, São Paulo, 21 mar. 2018. Disponível em:<https://noticias.uol.com.br/ultimasnoticias/afp/2018/03/21/argentino-muda-identidade-de-genero-para-anteciparaposentadoria.htm>. Acesso em: 26 maio 2018. 
GOIS, Ancelmo. Filha transexual de militar perde pensão da Marinha após mudar de nome e de sexo. O Globo, Rio de Janeiro, 14 set. 2017. Disponível em:

$<$ https://blogs.oglobo.globo.com/ancelmo/post/filha-transexual-de-militar-perde-pensao-damarinha-apos-mudar-de-nome-e-de-sexo.html>. Acesso em: 27 maio 2018.

HOFFMANN, Camila. O que é ser transgênero?. MundoPsicologos, [S.1.], 13 jun. 2016. Disponível em: $<$ https://br.mundopsicologos.com/artigos/o-que-significa-ser-transgenero $>$. Acesso em: 27 maio 2018.

IBRAHIM, Fabio Zambitte. Curso de direito previdenciário. 16.ed. Niterói: Impetus, 2011.

LEITE, Fernanda Capibaribe. Fronteiras que transbordam em cena: o transgênero como sujeito do dissenso em olhe para mim de novo. In: CONGRESSO INTERNACIONAL COMUNICAÇÃO E CONSUMO, São Paulo, 2014. Anais... São Paulo: ESPM, 2014. Disponível em:

<http://www3.espm.br/download/Anais_Comunicon_2014/gts/gt_nove/GT09_Fernanda_capi baribe.pdf>. Acesso em: 27 maio 2018.

MACEDO, Letícia. 'Ivan' da vida real, americano transgênero conta como foi ficar grávido e ter um filho. G1, São Paulo, 30 set. 2017. Disponível em:<https://g1.globo.com/mundo/noticia/ivan-da-vida-real-americanotransgenero-conta-como-foi-ficar-gravido-e-ter-um-filho.ghtml>. Acesso em: 27 maio 2018.

MATTOS, Carmem Lúcia Guimarães de. A abordagem etnográfica na investigação científica. In: __ _ CASTRO, Paula Almeida de (orgs.). Etnografia e educação: conceitos e usos. Campina Grande: EDUEPB, 2011. p. 49-83. Disponível em: $<$ http://books.scielo.org/id/8fcfr/pdf/mattos-9788578791902-03.pdf>. Acesso em: 30 maio 2018.

MENDES, Gilmar Ferreira. A Jurisdição constitucional no Brasil e seu significado para a liberdade e a igualdade. [S.1., 2010]. Disponível em:

$<$ http://www.stf.jus.br/arquivo/cms/noticiaartigodiscurso/anexo/munster_port.pdf $>$. Acesso em: 27 maio 2018.

MORAES, Guilherme Peña. Ações afirmativas no direito constitucional comparado. Revista da EMERJ, Rio de Janeiro, v. 6, n. 23, p. 298-315, 2003. Disponível em:

<http://www.emerj.tjrj.jus.br/revistaemerj_online/edicoes/revista23/revista23_298.pdf>.

Acesso em: 30 maio 2018.

NAÇÕES UNIDAS. Especialistas da ONU denunciam sequestros, tortura e assassinatos de LGBTs na Chechênia. ONUBR, Rio de Janeiro, 13 abr. 2017. Disponível em:

$<$ https://nacoesunidas.org/especialistas-da-onu-denunciam-sequestros-tortura-e-assassinatosde-lgbts-na-chechenia/>. Acesso em: 27 maio 2018.

NOVELINO, Marcelo. Manual de direito constitucional. 9.ed. rev. e atual. São Paulo: Método, 2014.

O DIA. Argentina libera atleta transexual para jogar com mulheres. O Dia, Rio de Janeiro, 29 abr. 2017. Disponível em:<https://odia.ig.com.br/esporte/2017-04-29/argentina-libera-atletatransexual-para-jogar-com-mulheres.html>. Acesso em: 27maio 2018. 
PLANO Mais Brasil PPA 2012-2015: agendas transversais: monitoramento participativo: ano base 2013. Brasília: Ministério do Planejamento, Orçamento e Gestão/SPI, 2014.

PRESIDENTE da Chechênia promete acabar com os gays até o fim de maio. Viajay, Salvador, 24 abr. 2017. Disponível em: <http://viajay.com.br/blog/visualizar/presidente-dachechnia-promete-acabar-com-os-gays-at-o-fim-de-maio>. Acesso em: 27maio 2018.

ROSSI, Marina; NOVAES, Marina. Os direitos básicos aos quais transexuais e travestis não têm acesso. El País: o jornal global, Madrid, 31 ago. 2015. Disponível em: <https://brasil.elpais.com/brasil/2015/08/28/politica/1440778259_469516.html〉. Acesso em: 27 maio 2018.

SALES, Ricardo. Responda rápido: você tem algum preconceito?. Associação Brasileira de Comunicação Empresarial, São Paulo, [2017]. Disponível em:<http://www.aberje.com.br/blogs/post/responda-rapido-voce-tem-algum-preconceito/>. Acesso em: 26 maio 2018.

SCRIVANO, Roberta; SORIMA NETO, João. Potencial de compras LGBT é estimado em R \$ 419 bilhões no Brasil: valor equivale a equivalente a 10\% do PIB. O Globo, Rio de Janeiro, 06 abr. 2015. Disponível em: <https://oglobo.globo.com/economia/potencial-decompras-lgbt-estimado-em-419-bilhoes-no-brasil-15785227>. Acesso em: 27 maio 2018.

SOUZA, Fábio Costa. Transgeneridade e sistema de proteção social no Brasil: o caso do sistema previdenciário brasileiro. Informe da Previdência Social, Brasília, v. 27, n. 10, out. 2015. Disponível em: < http://www.previdencia.gov.br/wpcontent/uploads/2016/06/informe_2015.10.pdf>. Acesso em: 26 maio 2018.

SUSTENTAÇÃO da primeira advogada transexual no STF é significativa, histórica e emocionante. Justificando: mentes inquietas pensam Direito, São Paulo, 8 jun. 2017. Disponível em: < http://justificando.cartacapital.com.br/2017/06/08/sustentacao-da-primeiraadvogada-transexual-no-stf-e-significativa-historica-e-emocionante/>. Acesso em: 27 maio 2018.

TRANSEXUAL tem direito a alterar registro civil mesmo sem cirurgia. Migalhas, [S.1.], 10 maio 2017. Disponível em: < http://www.migalhas.com.br/Quentes/17,MI258586,11049Transexual+tem+direito+a+alterar+registro+civil+mesmo+sem+cirurgia $>$. Acesso em: 26 maio 2018.

TRIBUNAL Europeu diz que Casamento Gay não é um Direito Humano. ANAJURE, [S.1.], 10 out. 2014. Disponível:<https://www.anajure.org.br/tribunal-europeu-diz-que-casamento-gay-naoe-um-direito-humano/>. Acesso em: 27 maio 2018. 